\title{
USING THE ANAL YTICAL HIERARCHY PROCESS IN COMPRESSING SCHEDULES OF CONSTRUCTION PROJECTS
}

\author{
Osama Moselhi* ${ }^{1}$ \\ Professor, Dept. of Building, Civil and Environmental Engineering \\ Concordia University \\ Montreal, QC, Canada \\ E-mail: moselhi@encs.concordia.ca \\ Nazila Roofigari-Esfahan \\ Graduate Student, Dept. of Building, Civil and Environ mental Engineering \\ Concordia University \\ Montreal, QC, Canada \\ E-mail: $\underline{\text { r roofig@encs.concordia.ca }}$
}

\begin{abstract}
This paper presents a new method for schedule compression of construction projects using the Analytical Hierarchy Process (AHP). The method utilizes a multi-objective decision environment in which, activities are queued for crashing based on priorities established in that environment. Schedule compression is a common function in the management of construction projects. A wide range of methods are introduced in the literature to perform schedule compression utilizing genetic algorithms, heuristic rules, near optimum solutions using Harmony search, and analogy with the direct stiffness method for structural analysis. Although all these methods consider only cost in the process of schedule compression, a recently conducted survey, by the authors, indicates that project managers consider more than one factor in this process. In fact, the lack of consideration of factors that are important to contractors and project managers has been attributed to the limited use of the existing methods. To address this need, using the results generated from the questionnaire survey, the newly developed method accounts for factors identified to be important from the conducted survey. These factors are resource availability, risk, complexity and logistics, contractor's confidence in the sub-contractor who is to execute the work, etc. A numerical example is analysed to demonstrate the use of the developed method and to illustrate its practical features.
\end{abstract}

Keywords: Analytical Hierarchy Process, Project schedule compression, Time-cost trade-off analysis, Schedule crashing, Project acceleration

\section{Introduction}

The time-cost trade-off analysis is usually needed in the execution phase of projects. This analys is is usually performed to establish the delicate balance between the overall cost of a project and its respective duration. That analysis typically leads to rational estimation of project least-cost duration, which is not necessarily identical to the original contractual duration. This analysis is also performed targeted milestones imposed by owners, or to make up for lost time due to delays experienced on site.

\footnotetext{
* Corresponding author

${ }^{1}$ The financial support of NSERC to the first author and that of the Faculty of Engineering and Computer Science are gratefully acknow ledged.
} 
A number of methods were introduced in the literature for solving the time-cost trade-off problem using optimization and heuristics. Optimization-based methods convert the problem into mathematical programming models using linear or dynamic programming (e.g. Kelley 1961; Elmaghrabi 1993). These models obtain the optimal solution of the problem but need considerable computational effort. Heuristic methods, however, provide a way to obtain good solutions but do not guarantee optimality. Different models have also been proposed in the literature using Genetic Algorithm (Que 2002), Harmony Search (Geem 2010), analogy with the direct stiffness method for structural analys is (Moselhi 1993) and iterative crashing process (e.g. Ahuja 1994). Recently, solutions for the problem have been expanded to take into account the time value for money using discounted cash flow model (Ammar 2011) and to consider project's profit as a vital objective that often determines the project success or failure, instead of its cost in performing the trade-off (Senouci and El-Rayes 2009).

All the methods cited above, consider only activities 'cost in performing the trade-off and shortening project's duration. The lack of consideration of additional factors that are likey to be important to contractors and project managers when planning to accelerate their projects has been attributed to the limited use and uptake of these methods in practice (Sears 2008). Thgis paper presents a method that accounts for not only cost but for other factors utilising the Analytical hierarchy process (AHP). The developed method also generates execution plans by assigning different weights for the decision variables. This provides contractors with flexibility of examining different plans and select the most suitable one. A numerical example is analyzed to demonstrate the additional features of the developed method and to illustrate its capabilities.

\section{Proposed method}

\section{Current practice}

To better understand the severity of the need for reducing schedules of EPC projects and the nature of the decision environment in which the schedule compression is performed, i.e. the factors that contractors and project managers consider when planning to shorten the duration of the ir project, a questionnaire survey was conducted. The questionnaire has been sent to a wide range of contractors and construction managers within Canada, United States and Middle East. The participants in the survey are seasoned professional having experience that ranges from 5 to 40 years (see Figure 1) in management of building projects, industrial facilities and power plants that range in value from $\$ 1$ million to \$ 3bilion.

To figure out the severity of the need for performing the schedule compression in EPC projects, the participants were asked about the number of projects in which they encounter the need for acceleration as a percentage of the total number of projects under their responsibility. Figure 2 illustrates the participants' answers to this question. As it is shown in this figure, all of the participants were encountered the need for accelerating the ir projects and none has declared not encountering such need. Figuring out the importance of the issue of schedule compression in practice, the participants were asked about the factors that they usually consider when planning to reduce the duration of the projects under their responsibility. As expected, all the participants selected to consider more than one factor in queuing activities for crashing. In other words, they consider not only cost, but also other factors in selecting the activity that should be crashed first in order to meet schedule constraints as well as projects' other environmental conditions. 

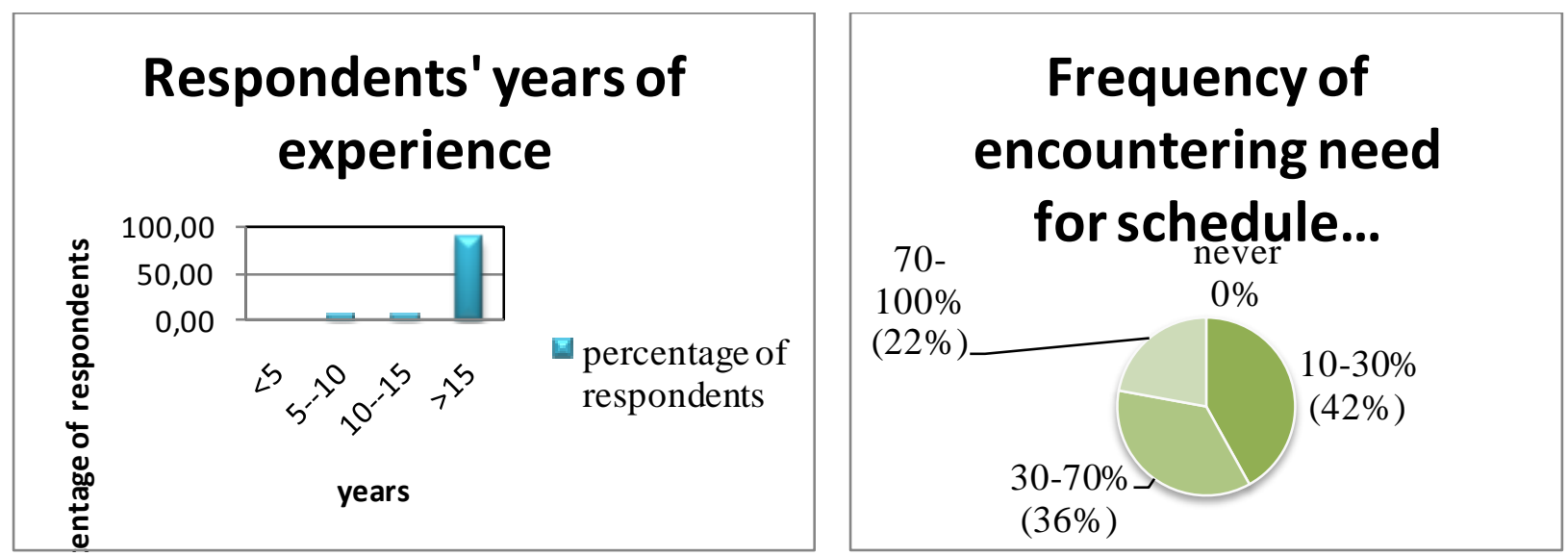

Figure 1: Respondents' years of experience

Figure 2: Frequency of encountering the need for schedule compression

Figure 3 illustrates the factors that have been identified to be important in the schedule compression process, i.e. in setting priorities for activity crashing. As it can be concluded from that figure, cost is among the most important factors that are considered in the process of schedule compression; but still factors such as resource availability, the risk associated with the project, complexity and logistics of the work and contractor's leverage on the subcontractor that is supposed to perform the job are deemed more important than activities added direct cost for one unit crashing, i.e. their cost slopes. This renders the available methods in the literature that are based on cost only to be of limited use and of not much uptake by contractors and project managers in practice. The findings of the conducted survey also show the need to model the problem as a multi-objective decision environment in which different factors contribute to queuing activities for crashing.

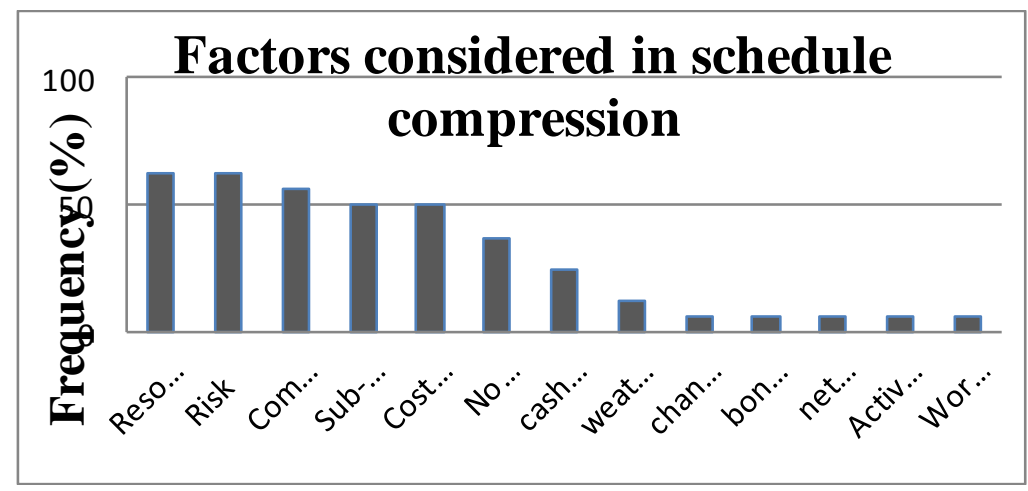

Figure 3: Factors considered important in schedule compression

\section{Decision environment}

To model the multi objective decision environment introduced in the previous section, the developed methodology utilizes the Analytical Hierarchy Process (Saaty 1980) along with the iterative crashing 
process (e.g. Stevens 1990; Ahuja 1994). The AHP is best suited to model this multi-attributed decision environment in view of its structured and well organized pair-wise comparisons process that encourages decision makers to study and evaluate the relative importance of the attributes considered in the process. This is particularly true in modeling the schedule compression problem, where contractors' intuitive judgment and perception of the problem constitute major consideration in priority setting for activity crashing.

Having mapped the decision environment and its multi-attributed nature, the relative importance of each attribute is then determined utilizing the process of pare-wise comparisons used in AHP method (Saaty, 1980). In other words, for attributes A1 to An, each attribute is individually compared to the rest of the attributes to generate a decision matrix [D] of the order $n \times n$ where " $n$ " represents the number of attributes considered for setting activity crashing priorities. In that matrix, $a_{i j}$ represents whether attribute $A_{i}$ is more important or less important than attribute $A_{j}$ using the following procedure (Saaty 1980):

If attribute $A_{i}$ is: Equally important to attribute $A_{j}, a_{i j}$ is set equal to 1 ; Weakly more important than $A_{j}, a_{i j}$ is set equal to 3; Strongly more important than $\mathrm{A}_{\mathrm{j}}, \mathrm{a}_{\mathrm{ij}}$ is set equal to 5; Demonstrably more important than $A_{j}, a_{i j}$ is set equal to 7; Absolutely more important than $A_{j}, a_{i j}$ is set equal to 9;

It follows that the lower triangle elements $\left(\mathrm{a}_{\mathrm{ji}}\right)$ are assigned a value equal to the reciprocal of the values of the upper triangle $\left(\mathrm{a}_{\mathrm{ji}}=1 / \mathrm{a}_{\mathrm{ij}}\right)$.

Upon constructing the decision matrix [D], at the project level, the relative weight vector $\{\mathrm{W}\}$ is then calculated as describe in Saaty (1980). It should be noted that these weights reflect the relative importance of each attribute in setting priorities for activity crashing. Pair-wise comparisons at the activity level is performed with respect to each decision attribute to ultimately generate the emphasis vectors $\{\mathrm{Eji}\}$ in the same way the weight vector is generated. The priority setting for crashing individual project activities can then be carried out using the following matrix formulation:

$$
\text { [4] }\{P\} m \times 1=\left[\left\{E_{j 1}\right\}\left\{E_{j 2}\right\} \ldots\left\{E_{j n}\right\}\right] m \times n \times\{W\} n \times 1
$$

Where: $\{\mathrm{P}\}=$ Priority vector; $\left\{\mathrm{E}_{\mathrm{ji}}\right\}=$ Emphas is vector w.r.t. attribute $\mathrm{i}$; and $\mathrm{m}=$ the number of activities being considered for crashing

The iterative crashing process is then commenced with crashing the activity with highest priority based on Eq. 4 and is repeated until that activity reaches its crashed duration or until a new critical path is formed. In the latter case, the priority setting procedure explained above is applied to generate the crashing priorities for the activities on the new critical path. All generated critical paths are then crashed simultaneously. If more than one critical path share a common activity, that activity will be crashed if its cost slope is less than the summation of cost slopes of the selected activities for crashing on each critical path. It should be noted that when more than one activity share the same priority for crashing, the following two rules of thumb are applied:

1. The activity w ith more number of successors should be crashed first;

2. The activity which finishes earlier should be crashed first;

The process of crashing continues until project reaches its least-cost duration, its targeted duration or until no further crashing is possible.

\section{Numerical example}

A numerical example drawn from literature (Ammar 2011) is analyzed to illustrate the capabilities of the developed model in performing the time-cost trade-off analysis in a multi-objective environment. The 
example was first presented by Moussourakis and Haksever (2004). The project network consists of 7 activities as shown in Figure 4. In this example, activities of the project have different time-cost relations, including linear, piece-wise linear and discrete. The indirect cost is assumed to be $\$ 6 /$ day. To enable the comparison between 3 methods, the total cost provided by Moussourakis are regenerated based on considering indirect cost equal to $\$ 6 /$ day. The proposed method is used to generate two scenarios for this example: (1) the base case, which considers only cost in search for project least-cost duration; and (2) scenario 2 in which resource availability (Ra), complexity and logistics of the work (Co) and cost slope (Cs) are considered as the 3 decision variables, i.e. attributes. Relative order of importance is $\mathrm{Ra}>\mathrm{Cs}>\mathrm{Co}$ is assumed for this scenario to enable the pair-wise comparisons needed in AHP. Also, in this scenario it is assumed that activity A has the most priority based on resource availability. As such, although its cost slope is higher than activity $\mathrm{E}$ from duration of 69 days to 65 days, it gains higher priority for crashing based on considering all the factors and is crashed until it reaches its crashed duration.
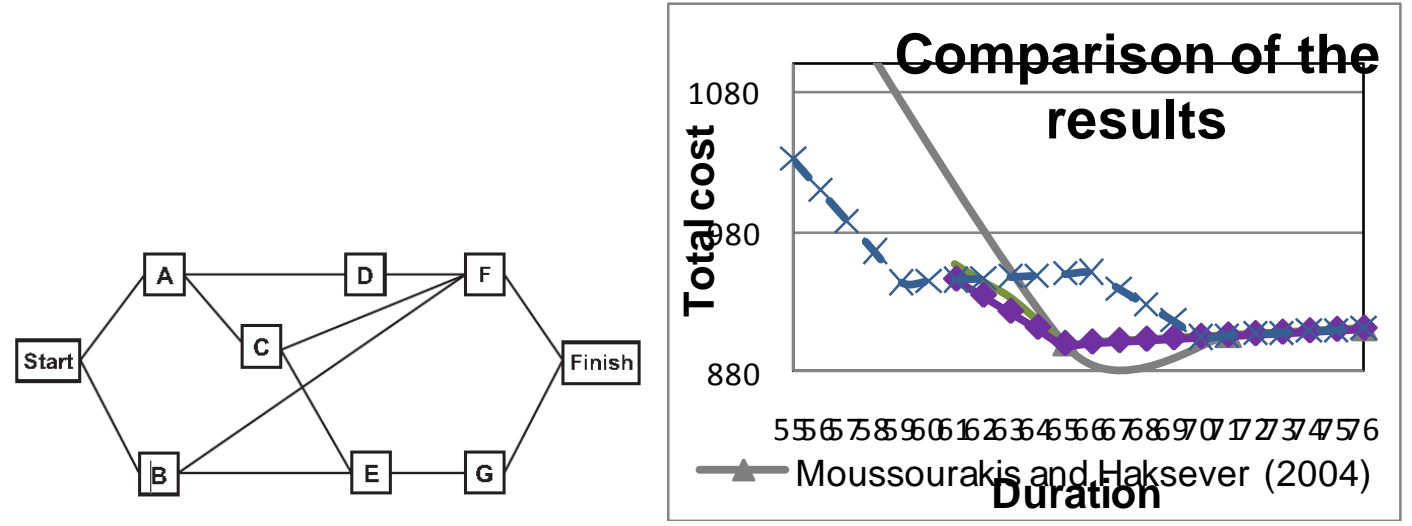

Figure 4: Network of the example project

Figure 5: Comparison of the results

Figure 5 illustrates the comparison of the results generated from these two scenario along with those provided by Ammar (2011) and Moussourakis and Haksever(2004). When considering only activities' cost, the developed method generated the same results as those provided by other authors. In second scenario, however, consideration of 2 other factors in addition to cost, as expected, resulted in different project least-cost and associate duration.

\section{Summery and concluding remarks}

The method presented in this paper models the decision environment for project scheduling compression accounting for a wide range of factors found to be in use and applied intuitively by contractors and construction managers. The analytical hierarchy process is utilized to model the multi-attributed decision environment. A numerical example was analyzed to demonstrate the use of the developed method and to illustrate its practical features. To study the impact of multi-attributed schedule compression two scenarios were generated from the original example and were analyzed and the results were compared with those generated by other authors. The results of cost consideration only indicate similar least-cost durations to those of other methods. In case of consideration of two factors in addition to cost slope, the proposed method yielded different project total cost from those of considering cost only and those provided by other methods. As a result, the method provides users with the flexibility of considering 
factors that accounts for their own organizations' financial and technical constraints as well as those emanating from project specific conditions. The developed method, as such, provides practical and doable project schedule compression plans that are likely to be successful in their implementation.

\section{REFERENCES}

Ahuja HN, Dozzy SP. and Abourizk, SM. (1994). Project management: Techniques in planning and controlling construction projects, 2nd Edition, John Wiley \& Sons: New York

Ammar,M.A. (2011). Optimization of project time-cost trade-off problem w ith discounted cash flows, Journal of Construction Engineering and Management, ASCE, 137(1), 65-71.

Elmaghraby SE. (1993). Resource allocation via dynamic programming in activity networks. European Journal of Operational Research 64,199-215.

Geem ZW. (2010). Multi-objective optimization of time cost trade-off using Harmony Search. ASCE, Journal of Construction Engineering and Management 136(6), 711-716.

Hinze JW. (2008). Construction planning and scheduling, 3rd Edition, Upper Saddle River, N.J.: Prentice Hall

Kelley JE. (1961). Critical-path planning and scheduling: Mathematical Basis. Operations Research 9(3),296-320.

Meredith JR. and Mantel SJ. (2006). Project management: A managerial approach. 6th Edition. Hoboken, NJ: John Wiley.

Moselhi O. (1993). Schedule compression using the direct stiffness method. Canadian Journal of Civil Engineering 20, 65-72.

Moussourakis,J. and Haksever,C. (2004). "Flexible model for time-cost trade-off problem". Journal of Construction Engineering and Management, 130(3), 307-314

Que BC. (2002). Incorporating practicality into Genetic Algorithm-based time-cost optimization. ASCE, Journal of Construction Engineering and Management 128(2), 139-143.

Saaty TL. (1980). The analytical hierarchy process: planning, priority setting, resource allocation. McGraw-Hall International book co: London, England

Sears S. Sears K. Sears G. A. and Clough, R.H. (2008). Construction project management. 5th Edition. John Wiley \& Sons: N.Y.

Senouci A and El-Rays K. (2009). Time-profit trade-off analysis for construction projects. Journal of Construction Engineering and Management, ASCE, 135(8), 718-725. 